\title{
Great expectations: students' educational attitudes upon the transition to post-secondary vocational education
}

\author{
Louise Elffers - Frans J. Oort
}

Received: 2 March 2011 / Accepted: 4 May 2012 / Published online: 3 June 2012

(C) The Author(s) 2012. This article is published with open access at Springerlink.com

\begin{abstract}
In this study, we examine students' educational attitudes upon the transition to Dutch senior vocational education (SVE), a transition associated with high dropout rates in the first year. Prior studies have identified differences in educational attitudes between sociodemographic groups. However, the mechanisms underlying those differences remain topic of debate: some studies point at differences in the school orientation and support in students' social communities outside school, others focus on differences in educational experiences between sociodemographic groups. Multilevel sequential regression analyses on a diverse sample of 1438 students in urban SVE schools reveal that students have very positive educational attitudes upon their transition to SVE. Ethnic minority students express particularly positive attitudes. School-related encouragement and support at home plays an important role in students' attitudes, but the attitudes of students from lower educated or ethnic minority communities are less related to this support. Prior school experiences play an essential, but occasionally counterproductive, role in students' attitudes upon transition, depicting the transition as a fresh new start for some, and an unwelcome threshold for others.
\end{abstract}

Keywords Educational attitudes - School transitions · Dropout ·

Vocational education

\section{Introduction}

School transitions form a difficult hurdle for many students (Alexander et al. 2001). Dropout rates typically increase in the first year after a transition (Tinto 1993; Dutch

L. Elffers $(\varangle) \cdot$ F. J. Oort

Research Institute Child Development and Education, University of Amsterdam, P.O. Box 94208, 1090 GE Amsterdam, The Netherlands

e-mail: 1.elffers@uva.nl 
Education Inspectorate 2002). While a transition can offer a welcome fresh start for some, transitions are difficult for all youth, as students need to integrate into a new social and academic environment (Alexander et al. 2001; Tinto 1993; Langenkamp 2010). Students from disadvantaged backgrounds in particular may encounter difficulties when making a transition (Roderick 1993). This picture holds especially true for the transition to senior vocational education (SVE) in the Netherlands. SVE is the post-secondary continuation of the vocational track in Dutch secondary education, which serves about $55 \%$ of the Dutch secondary school population (Dutch Ministry of Education Culture and Science 2010). More than half of all dropout in SVE occurs in the first year after the transition (Dutch Ministry of Education Culture and Science 2011). Like in many Western countries, dropout rates in SVE are socially and ethnically patterned: students from lower socio-economic backgrounds drop out more often, as do students with less educated parents, and ethnic minority students (OECD 2006; Dutch Ministry of Education Culture and Science 2009; Alexander et al. 2001). Students from those backgrounds have been found to drop out in the first semester after the transition to SVE in particular (Elffers 2011).

The attitudes with which students enter a new institution have been found to play a decisive role in their attainment after the transition (Bers and Smith 1991; Hausmann et al. 2007; Tinto 1993). Therefore, it is relevant to examine whether differences in educational attainment between socio-demographic groups are mirrored in the educational attitudes among those groups upon the transition to SVE. Prior studies have indeed identified differences in the educational attitudes between socio-demographic groups, most prominently between ethnic groups. However, the nature of those differences remains topic of debate. Fordham and Ogbu (1986) founded their renowned 'acting White' thesis on reports of oppositional attitudes towards school among AfroAmerican students in the US, which could offer an explanation for their lower achievement in education. However, a growing number of studies indicates that the educational attitudes among ethnic minority students resemble the attitudes of majority students or are even more positive. These findings point towards a gap between the educational attitudes and achievement among ethnic minority students (Alexander et al. 1994; Khattab 2003; Downey et al. 2009; Kao and Tienda 1998; Mickelson 1990; Van der Veen and Peetsma 2006).

Differences in how educational attitudes are defined, and at what stage in students' academic careers they are measured, may account for some of the contradictions in the findings of the abovementioned studies (Downey et al. 2009; Mickelson 1990; Tyson 2002). In addition, a range of explanations is offered in the literature to account for the differences in educational attitudes between socio-demographic groups. Whereas some studies attribute those differences primarily to socio-cultural differences, and particularly to the educational attitudes prevailing in students' social communities (Davies and Kandel 1981; Fordham and Ogbu 1986; Wigfield et al. 1998; McMillan and Reed 1994; McCarron and Inkelas 2006; Ryan 2000; Steinberg et al. 1992; Wentzel 1998), other studies suggest that they are mainly related to differences in students' educational experiences, and in the extent to which students evaluate their attitudes in the light of those experiences (Alexander et al. 1994; Eccleston et al. 2010; Eccles 1983; Hossler and Stage 1992; Tinto 1993; Tyson 2002). 
In this study, we look into the educational attitudes of students upon the transition to post-secondary vocational education in the Netherlands. Dutch schools for SVE, especially those in urbanized areas, serve a diverse population of students aged $16+$, with a substantial proportion of students from lower socio-economic and ethnic minority backgrounds. As students transferring to SVE have spent at least 12 years in education, their educational attitudes carry the traces of long-range experiences in education. Thus, the context of the transition to SVE offers excellent opportunity to study differences in the educational attitudes of students from various sociodemographic backgrounds, and the potential role of the social and academic context in those attitudes. By looking at the relevant yet understudied setting of the transition to post-secondary vocational education, we aim to expand the existing body of research on educational attitudes and school transitions, which is primarily based on research in Anglo-Saxon secondary and higher education. The research questions guiding our study are:

- Do the educational attitudes of students upon the transition to Dutch SVE differ according to socio-demographic background characteristics?

- What is the role of the school orientation and support in students' home environment in their educational attitudes upon the transition to SVE?

- What is the role of students' prior academic pathway and experiences in their attitudes upon the transition to SVE?

- Do the abovementioned factors interact in their relationship to students' educational attitudes?

\section{Theoretical background}

\subsection{Defining educational attitudes}

In previous works, the term 'educational attitudes' has been used to describe various dimensions of students' pro- or anti-school sentiments, their personal educational aspirations, and their expectations of their educational career. The term is often used to refer to students' general orientation towards school and the importance that students attach to education for their personal lives or careers (Downey et al. 2009; Mickelson 1990). Such attitudes can be defined in more and less contextualized ways: students have both context-specific attitudes towards their particular school and degree program (Anderman and Kaplan 2008), as well as a more universal orientation towards education or their role as a student (Anderman and Freeman 2004). Educational aspirations refer more specifically to students' personal plans or goals in education, which appears to be one of the most powerful predictors of academic achievement (Downey et al. 2009). Such aspirations can take the form of more abstract, or idealistic, goals about the educational level that students plan or hope to attain in their lives, or of more concrete, or short-term, goals, for instance regarding the completion of a class or degree program (Mickelson 1990; Buchmann and Dalton 2002; Deil-Amen and Lopez Turley 2007; Teachman and Paasch 1998). Last, when students transfer to a new school, they have certain expectations of their new school environment and how 
they will fit into this environment, both in social as well as academic terms (Tinto 1993).

The above mentioned dimensions of students' educational attitudes may overlap and affect each other, and are often studied together (Deil-Amen and Lopez Turley 2007). The term 'educational attitudes' can serve as an umbrella for those various dimensions, and we will use this umbrella term accordingly. In our study, we distinguish four dimensions of students' educational attitudes upon the transition to SVE, capturing both general and contextualized dimensions of educational attitudes. We examine students' expectations of their new school environment (expected institutional fit and expected academic fit), their aspirations with respect to the program they have enrolled in (educational aspirations) and their attitudes towards education in general (general educational attitudes).

\subsection{Socio-demographic differences in students' educational attitudes}

Educational attitudes predict educational attainment: if students report high aspirations, optimistic expectations, and positive feelings towards their education, they are more likely to succeed in school (Ekstrom et al. 1986; Schoon 2008; McMillan and Reed 1994; Rumberger 1995; Sewell and Shah 1968; Maehr and Meyer 1997; Morgan 2005; Tinto 1993). School dropouts generally report less positive school attitudes (Ekstrom et al. 1986). As students from lower socio-economic and ethnic minority backgrounds drop out more often, we may expect that those students report more negative attitudes towards school. While some studies indeed found more negative educational attitudes among those groups of students (Fordham and Ogbu 1986), other studies revealed an inverse pattern: students from lower socioeconomic and immigrant backgrounds generally report more positive attitudes towards their education (Alexander et al. 1994; Downey et al. 2009; Van der Veen and Peetsma 2006). Irrespective of the exact nature of the differences found, scholars point to both social and academic context factors to explain differences in the educational attitudes across various socio-demographic groups, as we will set out below.

\subsection{The social context}

The educational attitudes of close relatives or significant others in students' lives affect students' own attitudes (Khattab 2003; Davies and Kandel 1981; Sewell and Shah 1968). In particular, the influence of parents has been studied extensively in research on educational attitudes. Not only do parents act as "expectancy and value socializers" for their children (Eccles 1983), their important role as sources of social and practical support and guidance for the educational careers of their children is emphasized in various studies (Alexander et al. 2001; Ekstrom et al. 1986; Hossler and Stage 1992; Linnenbrink-Garcia and Fredricks 2008; McCarron and Inkelas 2006; McMillan and Reed 1994; Rumberger 1995; Schoon 2008; Trusty 1998). Parental influence on students' attitudes seems to be stronger than peer influence (Davies and Kandel 1981). Yet, peer attitudes appear to shape students' educational attitudes considerably as well (Chang and Le 2005; Ryan 2000; Steinberg et al. 1992), especially among 
adolescent students (Davies and Kandel 1981; Cotterell 2007; Wentzel 1998; Wigfield et al. 1998). Differences in the school orientation and support for students' school careers in their community may account for differences in their attitudes. While most parents have high expectations of their children's academic careers regardless of the family's socio-economic status (Khattab 2005), socio-economically disadvantaged communities, especially recent immigrant communities, may attach additional value to education as a means to pursue upward social mobility (Rothon et al. 2010). However, there seems to be more incongruity between the emotional and practical support provided by parents in disadvantaged communities (Alexander et al. 1994). Families with higher socio-economic status have better knowledge of the educational system, and better access to human and financial resources, to not only support their children's educational careers emotionally, but in more practical ways as well (Khattab 2005). We can conceptualize the emotional and practical resources in students' social networks supporting their academic career as a school-related dimension of their social capital (Stevens et al. 2007).

\subsection{The academic context}

The school environment has been found to affect educational attitudes substantially (Eccles 1983; Khattab 2005; Goodenow and Grady 1993; Kao and Tienda 1998; Maehr and Meyer 1997). Not only do teachers and classmates affect students' educational attitudes through expressing, directly or indirectly, their personal academic values and expectations, but students' experiences in education also shape their attitudes towards their current and future educational pathways (Eccles 1983; Hossler and Stage 1992; Nichols 2008; Tinto 1993; Goodenow and Grady 1993). Students have been encouraged or discouraged by prior interactions with teachers and classmates before entering a new school (Finn 1993), and some students make the transition in the course of gradual disengagement from school (Finn 1993; Rumberger 1995). Earlier experiences of failure in school can be an important reason for students to enter a new school with less positive attitudes (Tyson 2002). Students from lower socio-economic or ethnic minority backgrounds generally encounter more academic or behavioral difficulties in their school careers (Alexander et al. 1994; Finn 1993; Finn and Rock 1997), and have been found to report lower levels of emotional engagement in school (Marks 2000; Voelkl 1995). Such experiences could press down students' optimism about the next step in their educational careers. Thus, students' academic pathways can play an important role in shaping their educational attitudes upon the transition to a new school.

\subsection{The case of the transition to Dutch post-secondary vocational education}

The vocational track in Dutch post-secondary education offers degree programs with an explicit vocational orientation and strong ties to the labor market. SVE offers programs in engineering, health and social care, economics, and agriculture at four levels: assistant level (1), basic vocational level (2), full professional level (3), and specialist level (4), with program durations from one year (level 1) to four years (level 4). 
The Dutch post-secondary school system allows for moving up to subsequent degrees: graduation at one level in SVE enables students to continue to the next level, a level 4 SVE diploma gives access to higher professional education, which in turn can lead to access to university. The educational attitudes of students in school systems like the Dutch system, which sorts students into different educational trajectories at an early age, have been found to be more determined by the type of school they attend than in more comprehensive school systems (Buchmann and Dalton 2002). Students may experience a stigma of attending the lower track, perceiving that they are less worthy and need to lower their future aspirations (Arum and Shavit 1995; Khattab 2005). However, while SVE programs are primarily intended to prepare students for a direct transfer to the labor market after graduation, many SVE students aspire to move on to higher levels of post-secondary education instead, and numerous students indeed do so. In contrast, other students may transfer to SVE with the desire to leave school as soon as the legal obligation to attend school ends at their 18th birthday. Yet, irrespective of their personal goals, the transition to SVE is a major step for all students. They leave their familiar, and usually smaller, school behind, and need to integrate into a new institutional environment, which may cause both anxiety and excitement.

\section{Methods}

In this study, we look at students' educational attitudes upon the transition to SVE. We examine whether there are differences in educational attitudes according to students' socio-demographic background that may or may not mirror socio-demographic differences in academic achievement, and we assess the role of social and academic context factors in students' educational attitudes. Below, we provide an outline of the methods used to address these questions.

\subsection{Sample}

We conducted our study with a sample of 1438 first year students in SVE in the Netherlands. From the total number of 40 SVE school boards in the Netherlands, 10 boards were invited for participation in the study, based on (1) their urban setting, to assure socio-demographic diversity of the sample, and (2) the range of degree programs offered, to enable data collection in various degree programs and levels within one school board. The five school boards that agreed to participate represent the initial selection satisfactorily. Within each school board, first year classes were selected from the three main vocational sectors (engineering, economics, and health and social care) at all four SVE degree levels. Classes were selected during the summer break, before student enrollments were finalized, and before individual students were assigned to individual classes. A total of 61 classes participated in the study, with an average class size of 24 students. Participation in the study was voluntary for all students. As questionnaires were completed in a classroom setting under supervision of a teacher, in practice all students in a class completed a questionnaire, and we received no reports of students not willing to participate. Hence, it is unlikely that specific groups of students are over- or underrepresented in our study. This is confirmed by the descriptive statistics 
in Table 1, which correspond to available statistics of vocational education and urban schools in the Netherlands (Dutch Ministry of Education Culture and Science 2010; Knowledge Centre for Vocational Training and Labour Market 2010; Kuhry 1998; Scientific Council for Government Policy 2008; Dutch Ministry of Health Welfare and Sport 2010).

\subsection{Questionnaire}

A new self-report questionnaire was developed to suit the specific level and nature of SVE and its students. The questionnaire has been subjected to a pilot study before being finalized. Its psychometric properties were been assessed through reliability analyses and principle component analyses. Cronbach's alphas were satisfactory to good. All variables had a 5-point Likert-type scale (strongly disagree to strongly agree), except for the items on students' socio-demographic background and characteristics of their new school and program (school board, sector, level).

\subsection{Outcome variables}

We defined four outcome variables to measure students' attitudes upon transition. Two measures assessed students' expectations of their fit with their new educational environment: expected institutional fit (e.g. I think I will feel at home at this school, 3 items, $\alpha=.87$ ), referring to students' expected fit with the institution in general, and expected academic fit (e.g. I think this degree program suits me well, 7 items, $\alpha=.80$ ), referring to students' expected fit with the specific vocational program and sector. The variable educational aspirations (e.g. I really wish to graduate from this degree program, 3 items, $\alpha=.74$ ) reflects students' ambitions with respect to the degree program they have enrolled in. General educational attitudes (e.g. I think it is important to go to school, 7 items, $\alpha=.80$ ) refers to students' general valuing of education as a means to pursue their career goals.

\subsection{Explanatory variables}

In line with the theoretical framework and the related research questions, we distinguished three groups of explanatory variables, that were entered in sequential steps to the statistical models: (1) socio-demographic background characteristics, (2) social context variables, and (3) academic context variables. As indicators of students' sociodemographic background, we used measures of students' ethnic and socio-economic background. The ethnic background measure was based on self-report by the student of his/her ethnic identity. As indicators of students' socio-economic background, we included student statements about their parents' job status, highest educational level of the parents, and financial circumstances at home. Moreover, we took into account students' birth year and gender.

The social context variables comprised reports on students' school-related social capital: the amount of encouragement and support regarding their school careers that 
Table 1 Characteristics of a sample of 1438 students entering Dutch senior vocational education

\begin{tabular}{|c|c|}
\hline Characteristics & Percent \\
\hline \multicolumn{2}{|l|}{ Gender } \\
\hline Female & 53 \\
\hline Male & 47 \\
\hline \multicolumn{2}{|l|}{ Ethnic identity } \\
\hline Native Dutch background & 51 \\
\hline Moroccan background & 15 \\
\hline Turkish background & 12 \\
\hline Surinamese background & 9 \\
\hline Antillean background & 3 \\
\hline Other ethnic background & 10 \\
\hline \multicolumn{2}{|l|}{ Age } \\
\hline $16-17$ years & 58 \\
\hline $18-19$ years & 30 \\
\hline Older than 19 years & 12 \\
\hline \multicolumn{2}{|l|}{ Job status parents } \\
\hline Both parents have a job & 49 \\
\hline One parent has a job & 22 \\
\hline Both parents have no job & 14 \\
\hline Student doesn't know & 15 \\
\hline \multicolumn{2}{|l|}{ Highest education parents } \\
\hline Primary education or similar & 9 \\
\hline Secondary education or similar & 12 \\
\hline SVE or similar & 20 \\
\hline Higher education or similar & 19 \\
\hline Student doesn't know & 40 \\
\hline Financial problems in family & 18 \\
\hline \multicolumn{2}{|l|}{ School board } \\
\hline Board 1-intermediate urban area & 30 \\
\hline Board 2-intermediate urban area & 10 \\
\hline Board 3-highly urbanized area & 20 \\
\hline Board 4-highly urbanized area & 19 \\
\hline Board 5-highly urbanized area & 21 \\
\hline \multicolumn{2}{|l|}{ SVE sector } \\
\hline Economics & 34 \\
\hline Engineering & 29 \\
\hline Health \& social care & 37 \\
\hline \multicolumn{2}{|l|}{ SVE degree program level } \\
\hline Level 1 & 14 \\
\hline Level 2 & 32 \\
\hline Level 3 & 23 \\
\hline Level 4 & 31 \\
\hline \multicolumn{2}{|l|}{ Prior education } \\
\hline PVE with diploma & 62 \\
\hline PVE without diploma & 6 \\
\hline SVE with diploma & 10 \\
\hline SVE without diploma & 9 \\
\hline Other & 13 \\
\hline
\end{tabular}

students receive from their parents (e.g. My parents/guardians think it is important that I finish school, and I can talk to my parents/guardians about my school experiences, 5 items, $\alpha=.67$ ), peers (e.g. My friends think it is important to finish school, and My friends and I talk about school matters, 4 items, $\alpha=.68$ ), and their community in 
general (e.g. Outside school, there are enough people with whom I can discuss school matters, and Outside school, there are enough people who can help me with my school work, 2 items, $\alpha=.73$ ).

The academic context variables included the educational program that the student was enrolled in prior to entering SVE, with additional information on whether the student graduated in that program or not, the vocational sector that the student is about to enter (engineering, economics, health and social care), the school board ( 3 school boards in highly urbanized areas, and 2 school boards in intermediate urban areas), and the level of the degree program (level 1 to 4). Moreover, students' prior school experiences were measured using four scales: prior emotional engagement (e.g. I felt at home at my previous school, 3 items, $\alpha=.88$ ), prior academic engagement (e.g. I worked hard at my previous school, 6 items, $\alpha=.77$ ), prior contact with classmates (e.g. I had many friends at my previous school, 5 items, $\alpha=.81$ ), and prior contact with teachers (e.g. I had good relations with my teachers at my previous school, 6 items, $\alpha=.87)$.

\subsection{Data collection}

Data were collected in the first week of the academic year 2008/2009, at the moment students entered SVE. This scheduling prevented students' reports of their educational attitudes upon transition from being colored by actual experiences in their new school environment. Students filled in a questionnaire in the classroom under supervision of their teacher. All teachers were informed about the purpose of the study, and received an instructional handout. Students could hand in their questionnaire in a blank envelope. A short introductory statement about the purpose of the study was printed on the questionnaire, as well as a short privacy statement in which we guaranteed that no identifiable personal data would be reported.

\subsection{Statistical analysis}

Data were screened for meeting the assumptions of regression analyses. As missing values were limited and missing at random, we applied the expectation maximization algorithm to impute missing values (SPSS Inc. 2010). The intra-class correlation coefficient (ICC) indicated that a substantial part of the variance could be attributed to between-class differences, with ICC's ranging from .04 to .10. Therefore, multilevel regression analyses were carried out, with class and student included as two separate levels (Snijders and Bosker 1999). To facilitate the interpretation of the coefficients, we standardized variables to zero mean and unity variance. We conducted sequential regression analyses. First, we fitted a model which included students' sociodemographic characteristics only (Model 1). Then, we added the social context variables (Model 2). Third, we added the academic context variables (Model 3). In addition, we checked for first order interactions of all socio-demographic student characteristics with the social and academic context variables, by adding each interaction as a fixed variable to the third model one by one. 


\section{Results}

Table 2 shows the results of the multilevel sequential regression analyses.

Our data indicate that, on average, students have positive educational attitudes upon the transition to SVE, and especially high aspirations $(M=4.47$ on a scale from 1 to 5 , with 5 signifying the most positive score, $\mathrm{SD}=.51$ ). A model that only includes socio-demographic characteristics explains small proportions of variance for students' expectations ( $R^{2}=.02$ for both expected institutional fit and expected academic fit) and aspirations $\left(R^{2}=.04\right)$, and slightly more for their general attitudes $\left(R^{2}=.11\right)$. Including the social context variables increases the amount of explained variance of all four outcome variables substantially $\left(R^{2}=.11\right.$ to .22 ), and adding academic context measures increases the proportion of explained variance even more $\left(R^{2}=.15\right.$ to .29$)$.

\subsection{Socio-demographic patterns in students' educational attitudes}

Ethnic minority students report significantly more positive aspirations and general attitudes than Dutch majority students. There is no significant difference for students with an Antillean background, but this exception may be caused by their smaller representation in our sample. Students with an ethnic background other than the largest five ethnic groups (native Dutch, Moroccan, Turkish, Surinamese, Antillean) have equal or more positive aspirations and general attitudes, but expect less academic fit. The ethnic background coefficients remain significant after controlling for social and academic context variables in our models. We do not find a significant role of the level of parental education, except for a positive association between having parents who completed secondary education at most and students' expected institutional fit. Students with unemployed parents have more positive general attitudes towards education than students with working parents. Students who don't know if their parents work, which is likely an indication that they are not closely involved with their parents at the moment of measurement, expect a better academic fit. Male students report more negative educational attitudes, but this difference decreases when taking social and academic context variables into account. Financial problems in the family have no significant influence on students' educational attitudes in the models that include social and academic context variables. Only when we control for students' school-related social capital, we find an effect of year of birth, indicating that younger students have less positive educational attitudes upon transition.

\subsection{The role of the social context}

The encouragement and support of parents, peers and the community plays an important role in students' educational attitudes. Especially parental encouragement and support is important for all four dimensions of students' attitudes upon transition to SVE. Peer support particularly influences students' general attitudes, while peer support is less related to students' aspirations. School-related support from parents, peers and the broader community all remain substantial and significant in models with academic context variables added. 


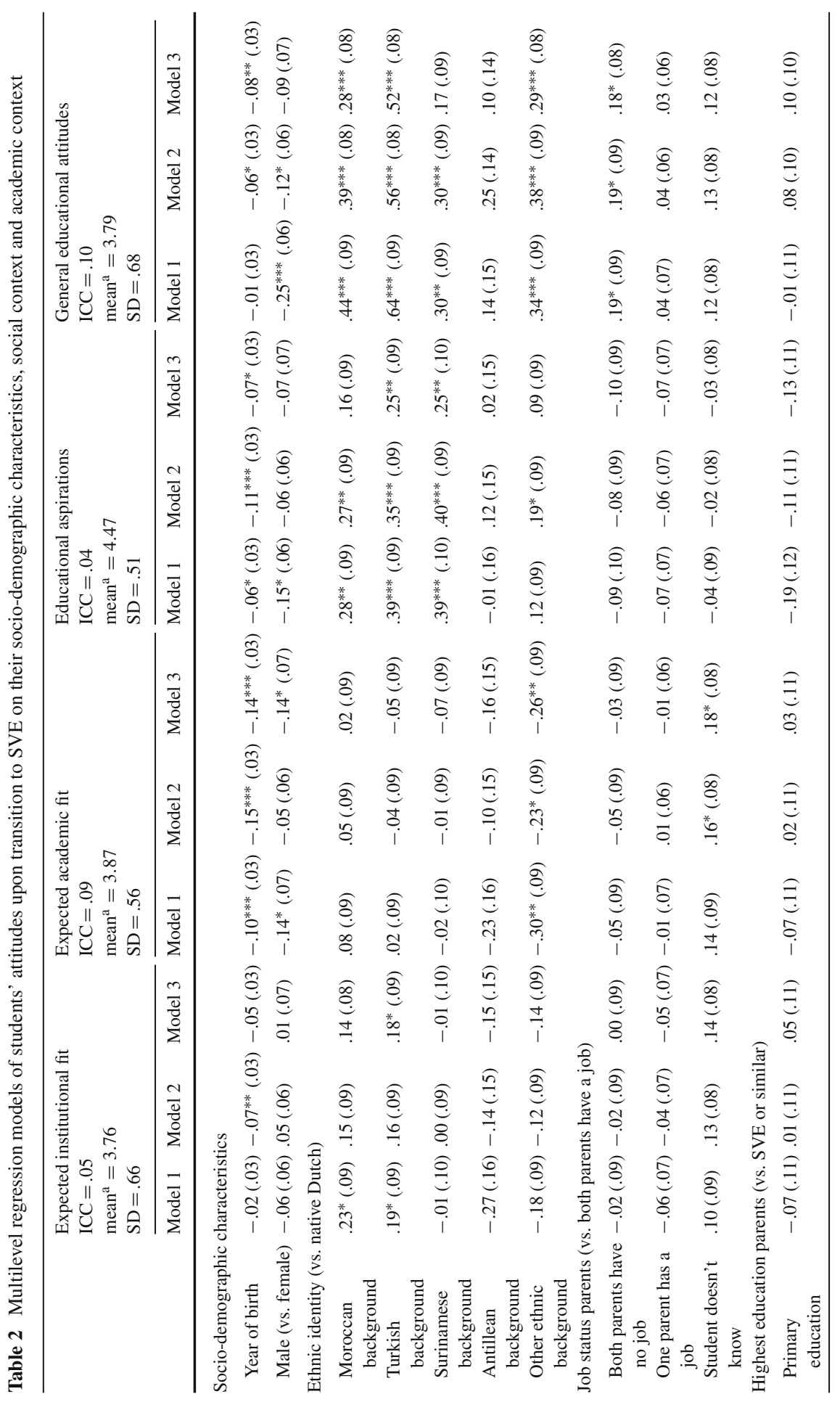




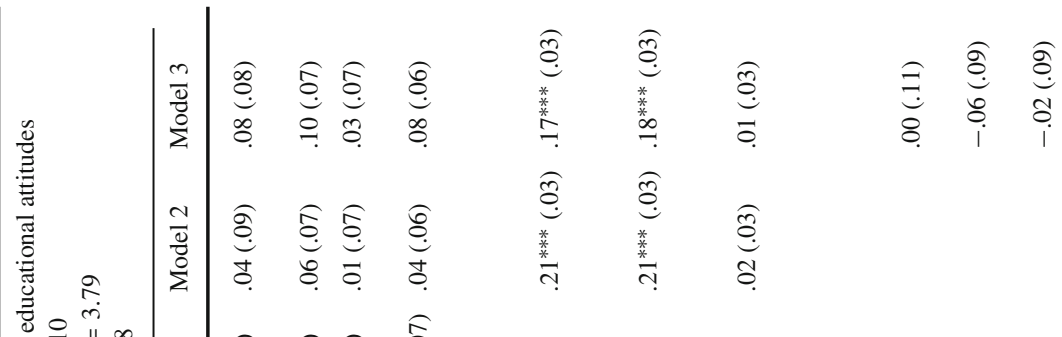

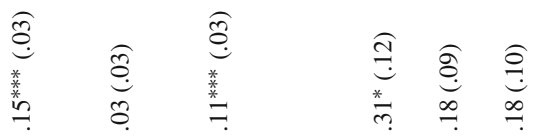

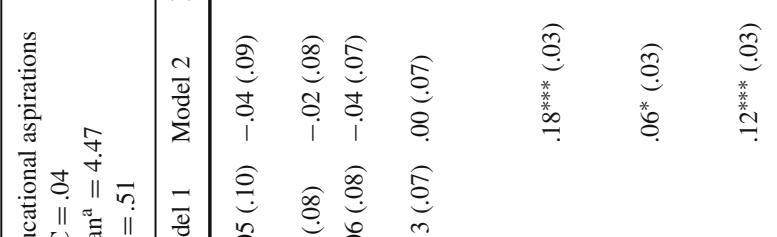

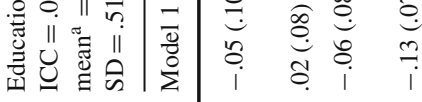

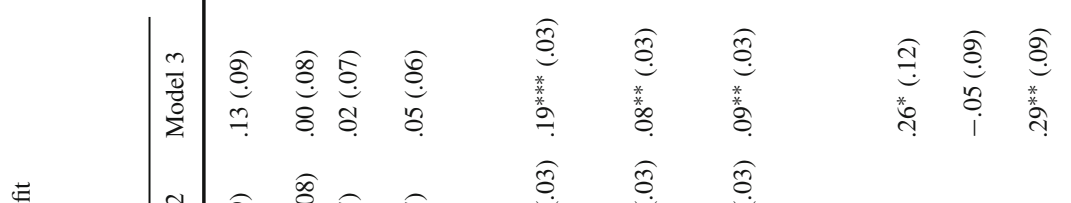

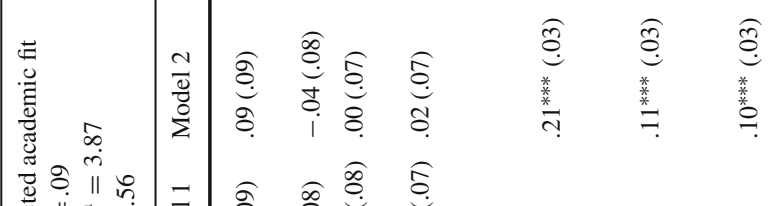

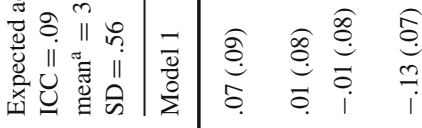

$$
\begin{aligned}
& \text { 总 }
\end{aligned}
$$

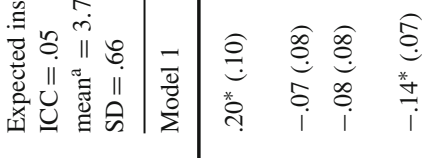

$$
\begin{aligned}
& \text { 善善憘 }
\end{aligned}
$$

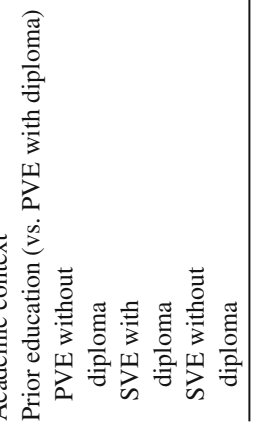




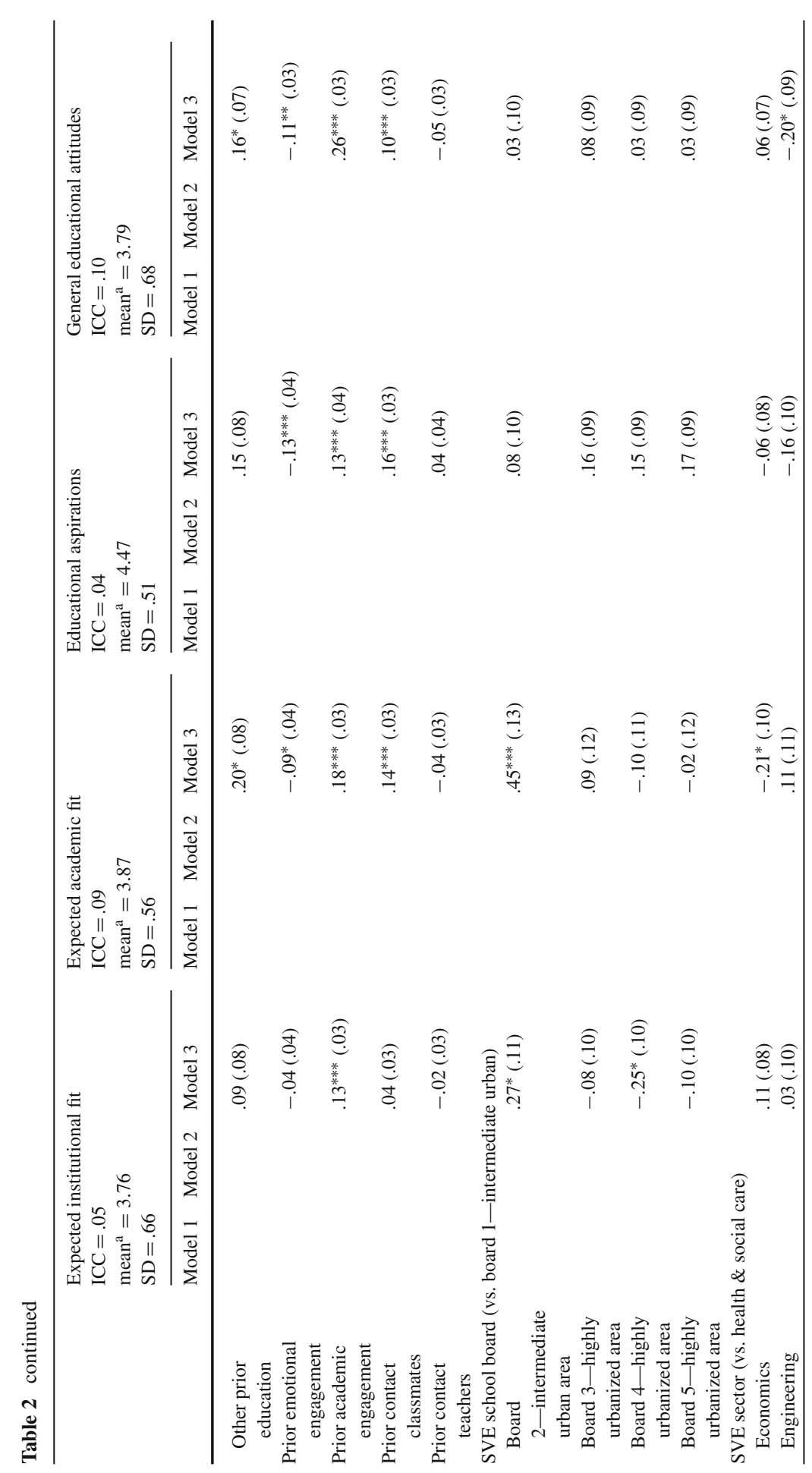




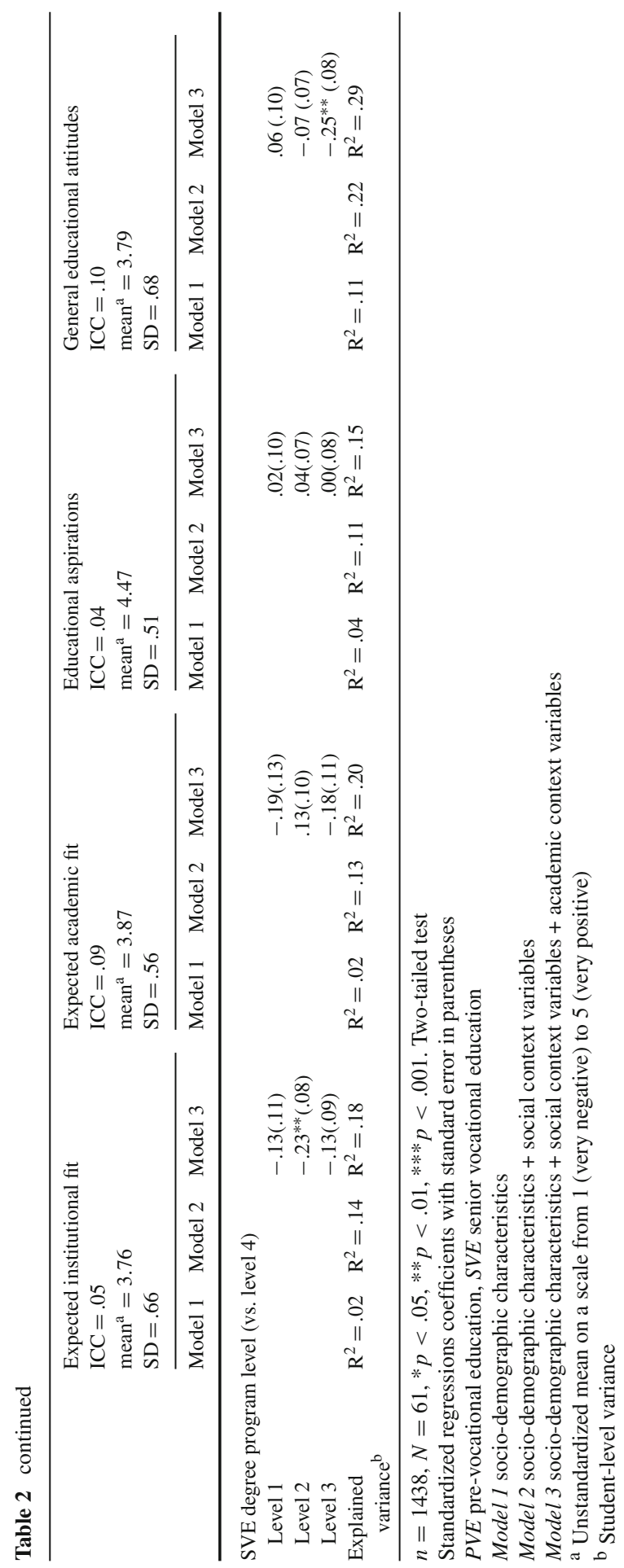




\subsection{The role of the academic context}

Academic context variables have significant influence on students' educational attitudes. In particular, students' prior academic engagement, but also their contact with classmates at their former school, associates with their educational attitudes. The perceived connection with teachers in the prior school is of less importance. Prior emotional engagement seems to affect students' educational attitudes negatively. The zero-order correlation between emotional engagement and attitudes is positive, but in a model that also includes other prior school experiences, the effect of prior emotional engagement on educational attitudes turns negative. Emotional engagement is a measure of students' overall perceived fit with the prior school, which may comprise various social and academic aspects of students' prior school experiences, such as the fit with classmates, teachers, or the curriculum. If we control for those specific aspects, a negative correlation between students' prior emotional engagement and their educational attitudes remains. Students attending schools in highly urbanized areas expect less fit with the institution than students transferring to schools in less highly urbanized areas. Students enrolling in an economics program are less certain of their academic fit with the program, while engineering students value education in general less. Some differences between students in different degree levels are found for expected institutional fit and general attitudes. Students who enter SVE after dropping out of pre-vocational education are more motivated for their new academic program in SVE, while students who make a second try after earlier enrollment in SVE are more confident about their fit with the institution and program. Students transferring to SVE from other academic routes expect a better academic fit and value education in general more.

\subsection{Interaction effects}

Assessment of first order interactions between socio-demographic characteristics and social and academic context variables revealed two interesting patterns. Above, we reported positive associations with educational attitudes of both an ethnic minority background and the amount of school-related support from parents. However, an earlier study of our data (Elffers 2012) showed that ethnic minority students report lower levels of school-related support from their parents. Inclusion of interaction effects in our third models showed that the level of parental support plays a smaller role in the attitudes of ethnic minority students than of students with a native Dutch background. An example of this interaction effect is given in Fig. 1 for students with a Surinamese background. In the group of students with lower levels of parental school-support, Surinamese students report higher educational aspirations than Dutch majority students, and their aspirations are less affected by an increase of parental support than the aspirations of Dutch majority students. We found similar interaction effects of a Surinamese background with parental support on expected academic fit, and of Moroccan and Surinamese backgrounds with community support on expected institutional and academic fit. Moreover, similar patterns were found for the interaction of the educational level of students' parents with the school-related support from parents or the 


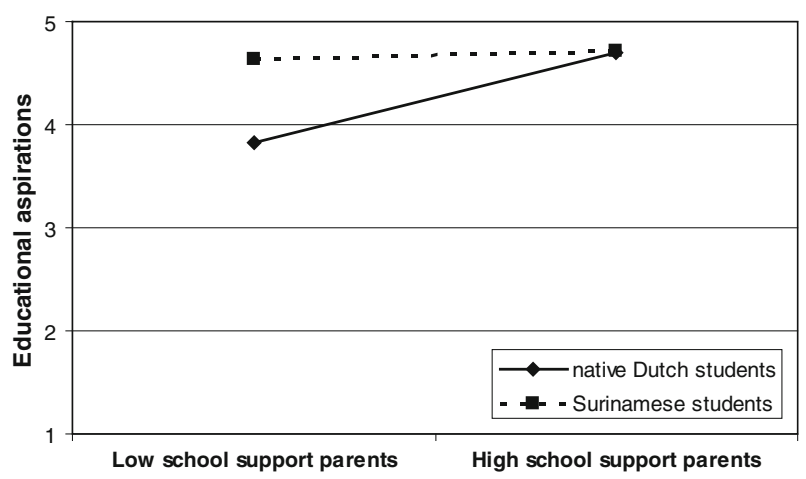

Fig. 1 Interaction effect of Surinamese background and school support parents on students' educational aspirations upon transition to SVE. Note plot based on 4 theoretical students who score zero on all other predictors

community, and of having financial problems or unemployed parents with parental support. For instance, the aspirations of students from poor families do not seem to benefit from increased parental support as much as the attitudes of students from more affluent families, and the same is true for the expected academic fit of students with unemployed parents or with parents who completed secondary education at most. The educational attitudes of those students appear to be less affected by lower levels of support. An interaction effect in the opposite direction can be found among students with higher educated parents: they expect a better academic fit if they report better access to supportive resources in their community.

Figure 2 shows an example of the second pattern of interaction effects: an interaction effect of students' prior education with their personal experiences in that prior education on their educational attitudes. Whereas we find an overall positive effect of students' prior educational experiences on their educational attitudes upon transition, interactions between students' prior education and their experiences in that prior education indicate a negative relationship in some situations. Students who were earlier enrolled in an SVE program, without graduating from that program, have higher aspirations if they were less academically engaged in the prior program, and have lower aspirations if they were previously more engaged. A similar interaction was found for this particular group with the level of prior emotional engagement and with contact with teachers at the prior school, on their expected institutional fit, aspirations, and general attitudes.

\section{Discussion}

Positive educational attitudes upon the transition to post-secondary education are critical for school success after the transition. High dropout rates among particular socio-demographic groups might seem to suggest that students from those groups may enter their new school with more negative attitudes. However, this study adds to the growing number of studies that indicate that students from lower socio-economic backgrounds or from ethnic minority groups do not report more negative educational attitudes. On the contrary, while ethnic minority students are overrepresented in SVE 


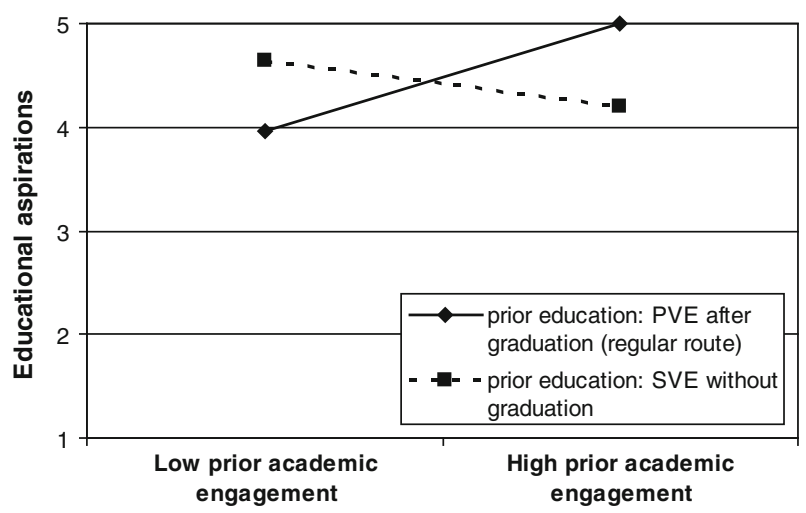

Fig. 2 Interaction effect of 'prior education: SVE without graduation' and prior academic engagement on students' educational aspirations upon transition to SVE. Note plot based on 4 theoretical students who score zero on all other predictors. $P V E$ pre-vocational education, SVE senior vocational education

dropout statistics in the Netherlands, those students report substantially higher aspirations and more positive general attitudes towards education. The same pattern is found for students from lower educated or poorer families. Thus, our results attest to the high ambitions among students hailing from those particular groups, which likely signifies a desire to pursue upward social mobility. Like students with lower educated parents, ethnic minority students, especially those growing up in first and second generation immigrant families, are often one of the first in their family to make the transition to post-secondary education, which makes them highly ambitious (Suárez-Orozco et al. 2009). Parents in those families are less experienced with the educational system, and may find it difficult to support their children in their school careers for that reason (Stevens et al. 2009). An earlier study based on our data confirmed that ethnic minority students, students with lower educated parents, and students from poor families, characteristics that are often clustered within the same families, report significantly lower levels of support for their school careers in their social communities (Elffers 2012). Inevitably, these youth have learned to navigate the educational system by themselves, causing a certain educational independence that can work out both beneficial and detrimental to school success. As students rely less on the support of relatives or significant others for their school careers, they are more autonomous and self-supportive. But this also means that they will encounter less monitoring, guidance and correction from the people who know them best. This mechanism is illustrated by our finding that, compared to other groups, the educational attitudes of students from lower socio-economic and ethnic minority communities are less related to the amount of school-related support in their environment. While in general students' educational attitudes are strongly related to the amount of school-related social capital in their environment, this is not the case for students from lower socio-economic or ethnic minority groups. The attitudes of students in those groups remain very positive, regardless of sufficient or limited access to school-related support in their social networks. 
Our findings imply that the potential negative effect of limited access to supportive resources on student achievement is not mediated by students' personal educational attitudes. This implication is consistent with the notion of the attitude-achievement gap, which describes the discrepancy between positive educational attitudes and negative achievement outcomes among disadvantaged students (Alexander et al. 1994; Downey et al. 2009). Furthermore, while lower levels of parental support seem to exert little negative influence over the educational expectations and aspirations of students from lower socio-economic or ethnic minority communities, those lower levels of parental support may limit students' prospects to realize those. Lower educated parents may think they are not capable of supporting their children, simply because they haven't completed many years of schooling themselves. However, our results imply that it is not the actual educational level of the parents that counts, but the schoolrelated support that they provide to their children. This result confirms Eccles' view that it is not the power of parents as role models that matters, but their role as direct socializers of achievement beliefs and attitudes (Eccles 1983).

School transitions are critical turning points in students' school careers, and will often be met with both excitement and anxiety. A transition to a new school is no isolated event, but rather an important threshold embedded in students' educational life-course. Whether students perceive a transition as a welcome new start or a disturbing interruption, or perhaps both, depends on their personal educational history. Our findings indicate that students with negative experiences in a previous SVE program are more eager to make a new start. Conversely, students with positive experiences in a previous SVE program, who apparently did not succeed in the program and therefore are required to make a new start, are more cynical about the prospects of their second try. These students may be especially at risk, as they apparently feel discouraged by the failure of the first try. These findings stress the importance for educators to learn about the educational history of their students. Intake interviews with transferring students can be used to find out about their prior school experiences, successes and failures, and to check for indicators of progressive disengagement from school.

\section{Conclusion}

Research on the educational attitudes of students in vocational tracks is scarce. This study contributes to earlier work on students' educational attitudes by expanding the focus to students transferring to post-secondary vocational education in Dutch urban areas. However, because of this specific context, we need to be careful to generalize our findings to other educational settings. Other limitations of the current study pertain to the measures used, and the cross-sectional design. First, our data result from students' self-reports. While the information on students' graduation before their transition informs us about their success or failure in their prior school program, no objective measures of prior academic achievement were available to include in our analyses. Prior grades or standardized test scores could be powerful predictors of students' educational attitudes upon transition. Future research could benefit from inclusion of such more objective measures. Second, we used retrospective measures of students' experiences in their previous education that were assessed at the same time as their 
expectations, aspirations, and attitudes. Such design calls for awareness not to make causal inferences based on our data.

Earlier research on the educational attitudes of disadvantaged students has mainly concentrated on students from socio-economically marginalized communities. Our study of students in the vocational track adds to this perspective by focussing on the educational attitudes of students who may experience academic marginalization, as they do not transfer to higher education after high school. It is often suggested that placement in a vocational track could result in a 'cooling out' of academic aspirations and expectations (Alexander et al. 2008; Arum and Shavit 1995; Khattab 2005). However, our study demonstrates that students in the Dutch vocational track do not show signs of cooled attitudes towards education. They start out in SVE with great expectations. An important next step in educational research is to examine the factors that help or hinder those students in turning their great expectations into great achievements.

Open Access This article is distributed under the terms of the Creative Commons Attribution License which permits any use, distribution, and reproduction in any medium, provided the original author(s) and the source are credited.

\section{References}

Alexander, K. L., Bozick, R., \& Entwisle, D. R. (2008). Warming up, cooling out, or holding steady? Persistence and change in educational expectations after high school. Sociology of Education, 81(October), 371-396.

Alexander, K. L., Entwisle, D. R., \& Bedinger, S. D. (1994). When expectations work: Race and socioeconomic differences in school performance. Social Psychology Quarterly, 57(4), 283-299.

Alexander, K. L., Entwisle, D. R., \& Kabbani, N. S. (2001). The dropout process in life course perspective: Early risk factors at home and school. Teachers College Record, 103(5), 760-822.

Anderman, L. H., \& Freeman, T. M. (2004). Students' sense of belonging in school. In Motivating students, improving schools. Advances in motivation and achievement (Vol. 13, pp. 27-63).

Anderman, L. H., \& Kaplan, A. (2008). The role of interpersonal relationships in student motivation: introduction to the special issue. The Journal of Experimental Education, 76(2), 115-119.

Arum, R., \& Shavit, Y. (1995). Secondary vocational education and the transition from school to work. Sociology of Education, 68(3), 187-204.

Bers, T.H., \& Smith, K.E. (1991). Persistence of community college students: the influence of student intent and academic and social integration. Research in Higher Education, 32(5), 539-556.

Buchmann, C., \& Dalton, B. (2002). Interpersonal influences and educational aspirations in 12 countries: The importance of institutional context. Sociology of Education, 75, 99-122.

Chang, J., \& Le, T. N. (2005). The influence of parents, peer delinquency, and school attitudes on academic achievement in Chinese, Cambodian, Laotian or Mien, and Vietnamese youth. Crime \& Delinquency, 51(2), 238-264.

Cotterell, J. (2007). Social networks in youth and adolescence. New York: Routledge.

Davies, M., \& Kandel, D. B. (1981). Parental and peer influences on adolescents' educational plans: Some further evidence. The American Journal of Sociology, 87(2), 363-387.

Deil-Amen, R., \& Lopez Turley, R. (2007). A review of the transition to college literature in sociology. Teachers College Record, 109(10), 2324-2366.

Downey, D. B., Ainsworth, J. W., \& Qian, Z. (2009). Rethinking the attitude-achievement paradox among blacks. Sociology of Education, 82(January), 1-19.

Dutch Education Inspectorate. (2002). Voortijdig Schoolverlaten in het Middelbaar Beroepsonderwijs [Early school leaving in SVE]. Utrecht: Inspectie van het Onderwijs.

Dutch Ministry of Education Culture and Science. (2009). VSV Atlas [Dropout atlas]. The Hague: Ministerie van OCW.

Dutch Ministry of Education Culture and Science. (2010). Kernciffers 2005-2009 [Primary Statistics 2005-2009]. Den Haag: Ministerie van OCW. 
Dutch Ministry of Education Culture and Science. (2011). Kerncijfers 2006-2010 [Primary Statistics 2006-2010]. The Hague: OCW.

Dutch Ministry of Health Welfare and Sport (2010). Nationaal kompas volksgezondheid-bevolking-scholing en opleiding [National compass public health-population-education]. www.nationaalkompas. nl/bevolking/scholing-en-opleiding. Accessed 11 Nov 2010.

Eccles, J. (1983). Expectancies, values, and academic behaviors. In J. T. Spence (Ed.), Achievement and achievement motives. Psychological and sociological approaches. San Francisco: Freeman \& Co.

Eccleston, C. P., Smyth, J. M., \& Lopoo, L. M. (2010). Unraveling the race paradox of achievement and self-views. Social Psychology of Education, 13, 1-18.

Ekstrom, R. B., Goertz, M. E., Pollack, J. M., \& Rock, D. A. (1986). Who drops out of high school and why? Findings from a national study. Teachers College Record, 87(3), 356-373.

Elffers, L. (2011). The transition to post-secondary vocational education: Students' entrance, experiences, and attainment. Enschede: Ipskamp Drukkers.

Elffers, L. (2012). One foot out the school door? Interpreting the risk for dropout upon the transition to post-secondary vocational education. British Journal of Sociology of Education, 33(1), 41-61.

Finn, J. D. (1993). School engagement and students at risk. Washington: National Center for Educational Statistics.

Finn, J. D., \& Rock, D. A. (1997). Academic success among students at risk for school failure. Journal of Applied Psychology, 82(2), 221-234.

Fordham, S., \& Ogbu, J. U. (1986). Black students' school success: Coping with the "burden of 'acting White",. The Urban Review, 18(3), 176-206.

Goodenow, C., \& Grady, K.E. (1993). The relationship of school belonging and friends' values to academic motivation among urban adolescent students. Journal of Experimental Education, 62(1), 60-71.

Hausmann, L. R. M., Schofield, J. W., \& Woods, R. L. (2007). Sense of belonging as a predictor of intentions to persist among african american and white first-year college students. Research in Higher Education, 48(7), 803-839.

Hossler, D., \& Stage, F. K. (1992). Family and high school experience influences on the postsecondary educational plans of ninth-grade students. American Educational Research Journal, 29(2), 425-451.

Kao, G., \& Tienda, M. (1998). Educational aspirations of minority youth. American Journal of Education, 106(3), 349-384.

Khattab, N. (2003). Explaining educational aspirations of minority students: The role of social capital and students' perceptions. Social Psychology of Education, 6, 283-302.

Khattab, N. (2005). The effects of high school context and interpersonal factors on students' educational aspirations: A multi-level model. Social Psychology of Education, 8, 19-40.

Knowledge Centre for Vocational Training and Labour Market. (2010). 4e Benchmark middelbaar beroepsonderwijs-bouwsteen studiesucces [4th benchmark senior vocational education-student success]. Nijmegen: KBA.

Kuhry, B. (1998). Trends in onderwijsdeelname [Trends in educational participation] (Vol. Sociale en culturele studies-25). Rijswijk: SCP.

Langenkamp, A. G. (2010). Academic vulnerability and resilience during the transition to high school: The role of social relationships and district context. Sociology of Education, 83(1), 1-19.

Linnenbrink-Garcia, L., \& Fredricks, J. A. (2008). Developmental perspective on achievement motivation. Personal and contextual influences. In J. Y. Shah \& W. L. Gardner (Eds.), Handbook of motivation science. New York, London: The Guilford Press.

Maehr, M. L., \& Meyer, H. A. (1997). Understanding motivation and schooling: Where we've been, where we are, and where we need to go. Educational Psychology Review, 9(4), 371-409.

Marks, H. M. (2000). Student engagement in instructional activity: patterns in elementary, middle, and high school years. American Educational Research Journal, 37(1), 153-184.

McCarron, G. P., \& Inkelas, K. K. (2006). The gap between educational aspirations and attainment for first-generational college students and the role of parental involvement. Journal of College Student Development, 47(5), 534-549.

McMillan, J. H., \& Reed, D. F. (1994). At-risk students and resiliency: Factors contributing to academic success. The Clearing House, 67(3), 137-141.

Mickelson, R. A. (1990). The attitude-achievement paradox among black adolescents. Sociology of Education, 63, 44-61.

Morgan, S. L. (2005). On the edge of commitment. Educational attainment and race in the United States. Stanford: Stanford University Press. 
Nichols, S. L. (2008). An exploration of students' belongingness beliefs in one middle school. The Journal of Experimental Education, 76(2), 145-169.

OECD. (2006). Where immigrant students succeed. Paris: OECD.

Roderick, M. (1993). The path to dropping out. Evidence for intervention. Westport: Auburn House.

Rothon, C., Arephin, M., Klineberg, E., Cattell, V., \& Stansfeld, S. (2010). Structural and socio-psychological influences on adolescents' educational aspirations and subsequent academic achievement. Social Psychology of Education, 14(2), 209-231. doi:10.1007/s11218-010-9140-0.

Rumberger, R. W. (1995). Dropping out of middle school: A multilevel analysis of students and schools. American Educational Research Journal, 32(3), 583-625.

Ryan, A. M. (2000). Peer groups as a context for the socialization of adolescents' motivation, engagement, and achievement in school. Educational Psychologist, 35(2), 101-111.

Schoon, I. (2008). A transgenerational model of status attainment: The potential mediating role of school motivation and education. National Institute Economic Review, 205, 72-82.

Scientific Council for Government Policy. (2008). Vertrouwen in de school [Trust in the school]. Amsterdam: Amsterdam University Press.

Sewell, W. H., \& Shah, V. P. (1968). Social class, parental encouragement, and educational aspirations. The American Journal of Sociology, 73(5), 559-572.

Snijders, T. A. B., \& Bosker, R. J. (1999). Multilevel analysis: An introduction to basic and advanced multilevel modeling. London: Sage Publishers.

SPSS Inc.. (2010). PASW statistics 17.0 command syntax reference. Chicago: SPSS.

Steinberg, L., Dornbusch, S. M., \& Brown, B. B. (1992). Ethnic differences in adolescent achievement: An ecological perspective. American Psychologist, 47(6), 723-729.

Stevens, P., Clycq, N., Timmerman, C., \& Van Houtte, M. (2009). Researching race/ethnicity and educational inequality in the Netherlands: A critical review of the research literature between 1980 and 2008. British Educational Research Journal, 2009, 1-39.

Stevens, P., Lupton, R., Mujtaba, T., \& Feinstein, L. (2007). The development and impact of young people's social capital in secondary schools. London: Centre for Research on the Wider Benefits of Learning.

Suárez-Orozco, C., Rhodes, J., \& Milburn, M. (2009). Unraveling the immigrant paradox. Disengagement among recently arrived immigrant youth. Youth \& Society (April 2009).

Teachman, J. D., \& Paasch, K. (1998). The family and educational aspirations. Journal of Marriage and the Family, 60(3), 704-714.

Tinto, V. (1993). Leaving college. Rethinking the causes and cures of student attrition. Chicago: University of Chicago Press.

Trusty, J. (1998). Family influences on educational expectations of late adolescents. The Journal of Educational Research, 91(5), 260-270.

Tyson, K. (2002). Weighing in: Elementary-age students and the debate on attitudes towards school among black students. Social Forces, 80(4), 1157-1189.

Van der Veen, I., \& Peetsma, T. (2006). Parents' expectations and the development in motivation for school of migrant and Dutch background students in the lowest level of secondary school in the Netherlands. Paper presented at the 10th international conference on motivation, Landau, Germany.

Voelkl, K. E. (1995). School warmth, student participation, and achievement. Journal of Experimental Education, 63(20), 127-138.

Wentzel, K. R. (1998). Social relationships and motivation in middle school: The role of parents, teachers, and peers. Journal of Educational Psychology, 90(2), 202-209.

Wigfield, A., Eccles, J. S., \& Rodriguez, D. (1998). The development of children's motivation in school contexts. Review of Research in Education, 23, 73-118.

\section{Author Biographies}

Louise Elffers completed this study at the Research Institute Child Development and Education, University of Amsterdam. She is currently employed at the Amsterdam Centre for Inequality Studies of the same university. Her research interests concern social and academic determinants of educational attainment, (in)equality in educational opportunities, and educational organization and policy, with a specific interest in vocational education. 
Frans J. Oort is professor of Methods and Statistics of Educational Research and director of the Graduate School of Child Development and Education, University of Amsterdam. His research interests include measurement and measurement bias, and statistical modeling, especially non-standard applications of structural equation modeling. 